\title{
One giant leap for mankind? A cost-utility analysis of abolishing the law of gravity
}

Background: Canada's Neo Rhino Party, a joke political party created in 2006 as a successor to the Parti Rhinocéros, is planning a new regulation to repeal the law of gravity, which could have an important impact on diseases attributable to gravity on earth.

Methods: We sought to estimate the number of qualityadjusted life-years that would be saved if the proposed regulation is passed and determine the cost-effectiveness of adapting Boris Volfson's antigravity machine ${ }^{1}$ for use on earth. We performed an economic analysis using a hidden Markov model.

Results: Our results suggest that a microgravity environment would save over 2 million quality-adjusted life-years. The cost for every quality-adjusted life-year saved is estimated to be $\$ 328$.

Interpretation: Microgravity is the solution to the health care crisis in Canada. In addition, using technological, statistical and medical jargon gives us the opportunity to defy the laws of physics, mathematics and medicine.

C anada's Neo Rhino Party is a joke federal political party that was created in Montréal, Quebec, in 2006 as the successor to the Parti Rhinocéros. Commonly called the Rhinoceros Party in English, this party was a registered political party in Canada from the Ig6os to the I9gos. It was founded in 1963 by Jacques Ferron, a Canadian physician and author. The party's basic credo was "a promise to keep none of our promises." Its election platforms comprised impossible schemes that were designed to amuse and entertain the voting public. Some Rhinoceros Party promises included reducing the speed of light because it's much too fast, paving Manitoba to create the world's largest parking lot, providing higher education by building taller schools and repealing the law of gravity. When this last promise was made in the I98os, it was unthinkable, that is, until Boris Volfson of Huntington, Indiana, received US Patent 6960975 for his design of an antigravity machine. ${ }^{1}$ The Neo Rhino Party is currently planning a new regulation to repeal the law of gravity that could have an important impact on diseases and other health outcomes attributable to gravity on earth.

\section{Methods}

We sought to estimate the number of quality-adjusted lifeyears that would be saved if the Neo Rhino Party succeeds in repealing the law of gravity. We also sought to analyze the cost-effectiveness of adapting Volfson's antigravity device for use on earth as a means to diminish the burden of disease attributable to gravity. Volfson's invention is a method for generating a pressure anomaly of an inflationary vacuum state using the following steps (some occurring simultaneously): providing a space vehicle comprising a hollow superconductive shield, an inner shield, a support structure, upper and lower means for generating an electromagnetic field, electric motors, a power source, lifesupport equipment, a flux modulation controller and a crew; generating electrical energy in the power source; and converting this electrical energy into an electromagnetic field, thus creating an area of relatively lower vacuum pressure density (Figure I).

\section{The model}

A Markov model is a useful way to prove cost-effectiveness. This model is infinitely flexible and offers many opportunities to test assumptions, which enables us to generate data and pick those that support our case most effectively. We opted to use a hidden Markov model - a statistical model in which the system is assumed to be a Markov process with unknown parameters - to perform our cost-utility analysis. The challenge was to determine the hidden parameters from the observable parameters. In a regular Markov model, the state is directly visible to the observer, therefore the state transition

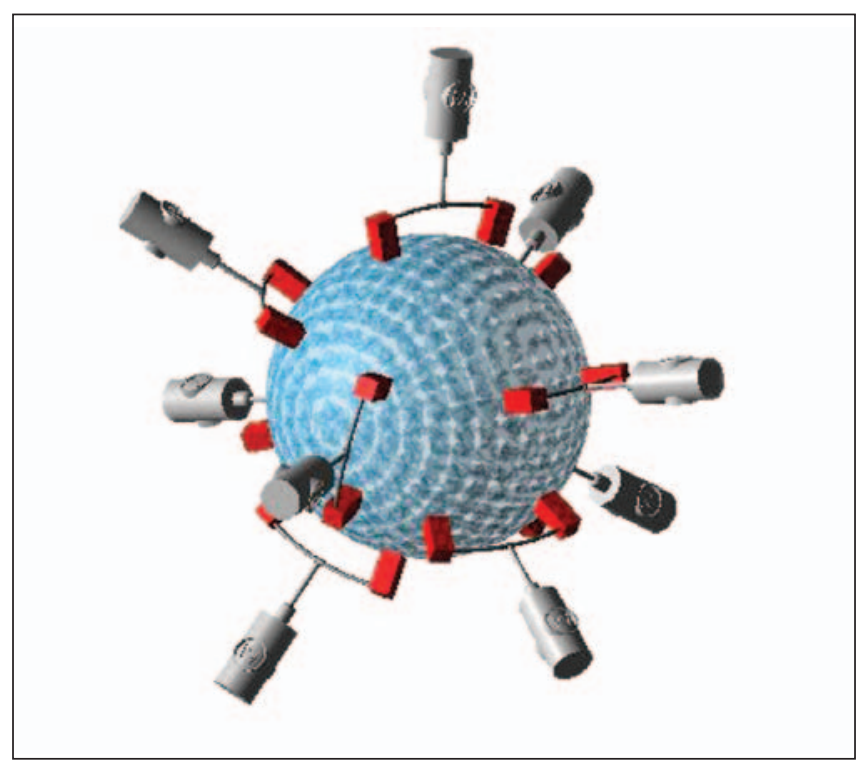

Figure 1: Illustration of Boris Volfson's antigravity device (reproduced with permission). ${ }^{1}$ 


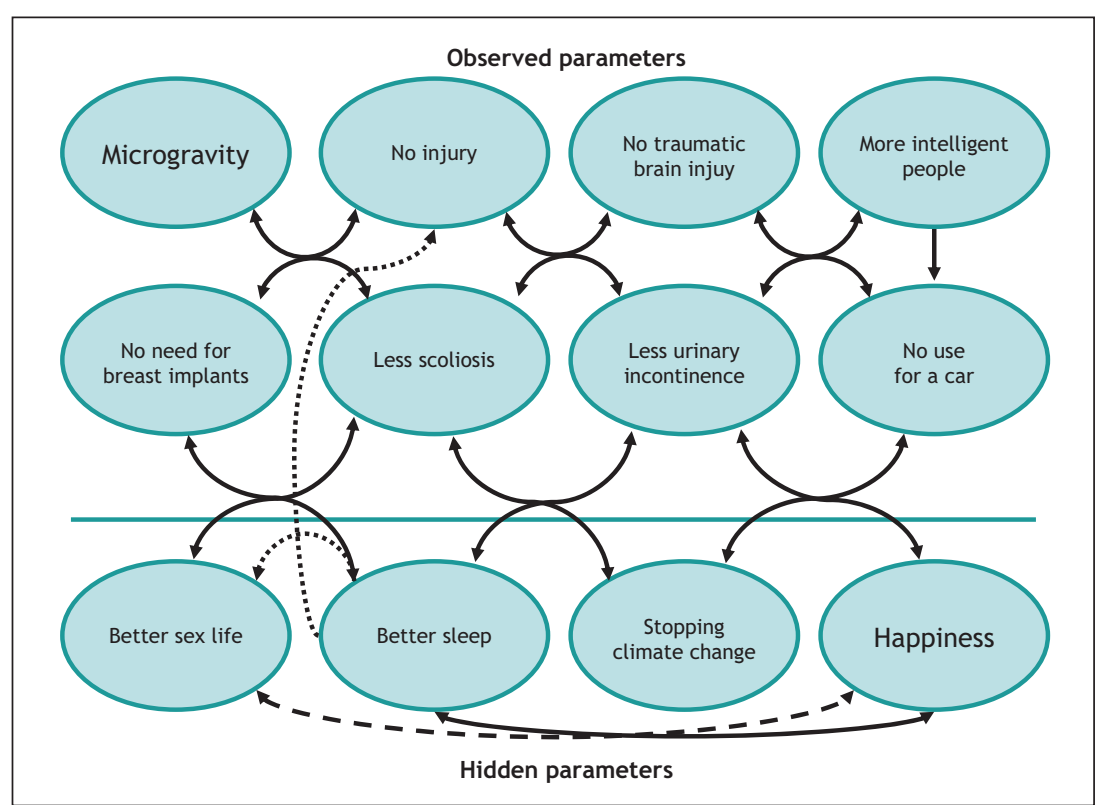

Figure 2: The Hidden Markov Model. morphic test dummies, animals, cadavers and live human (astronauts) test subjects in microgravity resulted in about I million quality-adjusted life-years saved.

Creating a microgravity environment each day between the hours of 7 am and 3 am the next day would save 2025036 quality-adjusted life-years according (only) to our estimate (Table 2). Microgravity would resolve the obesity crisis and the health care costs associated with obesity. For example, considering that weight equals mass times gravitational acceleration ( $\mathrm{w}=\mathrm{m} \times \mathrm{Ga})$, a man weighing $100 \mathrm{~kg}$ and measuring $175 \mathrm{~cm}$ in height would see his body mass index reduced from $32.7 \mathrm{~kg} / \mathrm{m}^{2}$ to $16.3 \mathrm{~kg} / \mathrm{m}^{2}$ in a microgravity environment (0.5 G).

\section{Interpretation}

Our study demonstrates that microgravity is the solution to the health care crisis in Canada. To virtually guarantee that our intervention probabilities are the only parameters. In a hidden Markov model the state is not directly visible, but variables influenced by the state are visible (Figure 2).

\section{The analysis}

We fit cost and health benefit factors within our model. Table I lists the factors included in our cost-utility analysis. We investigated the problems in abolishing gravitational force, namely the generation of endless energy to create the space-time curvature modification needed for Volfson's antigravity machine. We think that the nuclear power of the US and Russian Federation armies and the "civil" nuclear programs of North Korea and the Islamic Republic of Iran would be sufficient to generate the required energy supply. Table 2 lists the number of quality-adjusted life-years saved as a result of microgravity for diseases and other health outcomes. In order to limit negative physiologic effects owing to a microgravity environment, we will be required either to perform complicated threshold analyses or simply build the antigravity device with an intensity regulator to permit the presence of gravity between 3 am and 7 am each day. We also assumed that, in a microgravity environment, cars would not be useful and that transportation would be necessary only for overseas travel. As a result, the use of fossil fuels would decrease by $90 \%$, solving the problem of greenhouse gas emissions and stoping climate change. This, in turn, would lead to fewer hurricanes and floods, resulting in fewer injuries, deaths and other health-related outcomes.

\section{Results}

The cost of adapting the antigravity device to potentially save 2025036 quality-adjusted life-years would be \$Can666 million, resulting in a cost of $\$ C$ an 328 per quality-adjusted lifeyear saved (Table I). Mechanical testing using anthropo- presents an incremental cost-effectiveness ratio, we followed 3 simple rules, which conveniently allowed us to add and subtract facts to make our case stronger: ${ }^{2}$

- when there is little empirical research evidence of good quality, generate your own estimates;

- use as much technical jargon as possible; and

- do not worry readers with the intricacies of our model and just report the bottom line.

This study presents tons of limitations. A large volume of data exists to document the multiple detrimental physiologic effects of microgravity exposure on human physiology.$^{3-6}$ Organ systems, including the cardiovascular, neurohumoural, immune, hematopoietic and musculoskeletal systems, may be particularly affected. However, our research suggests that these physiologic effects can be mitigated by building the

Table 1: Cost of adapting Boris Volfson's antigravity device ${ }^{1}$ for use on earth

\begin{tabular}{lc}
\hline Element of the antigravity device & Can\$, millions \\
\hline Power source* $^{*}$ & 300 \\
Upper means for generating an & 200 \\
electromagnetic field* & \\
Hollow superconductive shield (inner shield) & 100 \\
Upper rotating element & 40 \\
Support structure & 20 \\
Flux modulation controller & 3 \\
Intensity regulator† & 3 \\
\hline Total & 666 \\
\hline
\end{tabular}

*Energy derived from nuclear weapons with cooperation from the US and Russian Federation armies and from the "civil" nuclear programs of North Korea and the Islamic Republic of Iran.

†Intensity regulator allowing the presence of gravity between 3 am and 7 am each day is needed to offset negative physiologic effects due to microgravity exposure. 
Table 2: Number of quality-adjusted life-years saved as a result of microgravity, by event or condition

\begin{tabular}{|lr}
\hline Event or condition & $\begin{array}{r}\text { No. of quality-adjusted } \\
\text { life-years saved* }\end{array}$ \\
\hline Car crashes & 1000000 \\
\hline Obesity & 1000000 \\
\hline Bicycle injuries & 10000 \\
\hline Falls (seniors) & 10000 \\
\hline Hurricanes, floods and other events & 5000 \\
related to climate change & 15 \\
\hline Defenestration & 5 \\
\hline Arthrosis & 5 \\
\hline Orthostatic hypotension and syncope & 4 \\
\hline Pressure ulcers & 1 \\
\hline Erectile dysfunction & 1 \\
\hline Gastroesophageal reflux while & 1 \\
\hline sleeping & 2 025 \\
\hline Glaucoma & 1 \\
\hline Lombalgia & 1 \\
\hline Parachute accidents & 1 \\
\hline Scoliosis & \\
\hline Varicose veins & 1 \\
\hline Total & \\
\hline Balpark figur. & 1 \\
\hline
\end{tabular}

*Ballpark figure.

antigravity device with an intensity regulator to permit the presence of gravity between 3 am and 7 am each day.

In addition, we only looked at the positive side of microgravity. We did not consider the medical problems (e.g. increased constipation and gastroesophagal reflux) or technical problems (e.g., wigs, intravenous fluids and toilets) related to the absence of gravity.

Furthermore, although we expect that, with a resolution from the United Nations, the United States, Russia, North
Korea and the Islamic Republic of Iran would promptly, and with a great sense of altruism, work together for the wellbeing of humankind by providing the nuclear power to generate the energy supply required for the antigravity device, the cooperation of these countries is only hypothetical.

Finally, in our model, we tried to take into account the probability of human-airplane crashes that would result from "giant leaps" owing to microgravity. We considered that human-airplane collision probability depends on the relative position-error covariance matrix in the encounter region, and that the probability of a jumping human hitting an aircraft depends on the combined position-error covariance and headpositioning-error covariance. The potential number of human-airplane crashes could limit the benefit of a microgravity intervention; however, a new law to regulate minimal flight altitude would diminish the impact of this inconvenience.

In conclusion, we proved that technological, statistical and medical jargon can convince intelligent people to read a manuscript. The proof? You're reading it!

\section{Claude Cyr MD \\ Pediatrician \\ Luc Lanthier MD \\ Internist \\ Sherbrooke, Que.}

\section{REFERENCES}

I. Handwerk B. Antigravity machine patent draws physicists' ire. National Geographic News. 2005 Nov II. Available: http://news.nationalgeographic .com/news/2005/II/IIII_05IIII_junk_patent.html (accessed 2007 Oct 23).

2. Burls A, Sandercock J. How to make a compelling submission to NICE: tips for sponsoring organisations. BMJ 2003;327:1446-8.

3. Da Silva MS, Zimmerman PM, Meguid MM, et al. Anorexia in space and possible etiologies: an overview. Nutrition 2002;18:805-I3.

4. Karemaker JM, Stok WJ, Latham RD. Body position and volume status as determinants of cardiovascular responses to transition into microgravity in parabolic flight. Physiologist 1993;36(I Suppl):S56-7.

5. Pantalos GM, Bennett TE, Sharp MK, et al. The effect of gravitational acceleration on cardiac diastolic function: a biofluid mechanical perspective with initial results. Curr Pharm Biotechnol 2005;6:33I-4I.

6. Schroeder MJ, Phaniraj V, Koenig SC, et al. The role of arterial elastance in ventricular-arterial coupling in normal gravity and altered acceleration environments. Aviat Space Environ Med 200I;72:I-7. 